\title{
Formação de professores do ensino superior e satisfação profissional
}

\author{
Higher education teacher training and career fulfillment
}

\author{
Viviane Assunta Oliveira Jeronimo (iD https://orcid.org/0000-0001-6381-1298 \\ Universidade da Amazônia \\ E-mail: v.jeronimo@hotmail.com
}

Rosângela Araújo Darwich (iD https://orcid.org/0000-0001-7325-9097
Universidade da Amazônia
E-mail: rosangela-darwich@unama.br

Resumo

Este estudo descritivo objetiva relacionar a avaliação subjetiva de satisfação profissional a investimentos na área realizados por professores do ensino superior de um curso de bacharelado e outro de licenciatura. Como fontes para o levantamento de dados foi utilizado um questionário online e realizada consulta à Plataforma Lattes do CNPq. Seis professores de uma instituição de ensino superior privada de Belém, no Pará, foram selecionados de um total de dezesseis respondentes por terem indicado sentir muita satisfação ou muita insatisfação na área profissional, avaliada desde o período anterior, de formação inicial. A interpretação dos resultados derivou da realização de análises funcionais, nos moldes da Análise do Comportamento. Os resultados destacam que as mesmas variáveis justificam o reconhecimento de satisfação ou de insatisfação por parte dos professores. Assim sendo, a percepção individual de fatores externos e pessoais reflete relações entre ações e emoções, evidenciando o valor de agregar sentido e prazer às atividades que precisam ser desempenhadas. O estudo permite concluir que, da mesma forma que a carreira profissional, satisfação com ela é obra de cada um, sendo inúmeros os percursos possíveis para que professores se sintam e se percebam - ou não - realizados profissionalmente. A perspectiva de análise adotada contribui para o reconhecimento de alternativas que priorizem o exercício da profissão aliado à qualidade de vida.

Palavras-chave: Docência. Formação profissional. Satisfação profissional.

\begin{abstract}
This descriptive study aims to relate the subjective assessment of career fulfillment to investments done by higher education teachers. We collected data through an online questionnaire and from the CNPq Lattes Platform database. From a total of 16 teachers from a private higher education institution in Belém, Pará, six were selected, who indicated that they felt very satisfied or very dissatisfied in the professional area since the previous period of initial training. Performing functional analysis along Behavior Analysis principles provided the interpretation of the results. The results highlight that the same variables justify the recognition of satisfaction or dissatisfaction by the teachers. Therefore, the individual perception of external and personal factors reflects relations among actions and emotions, showing us how important it is to turn one's performance meaningful and pleasant. The study allows us to realize that both, career and satisfaction with it, are an individual issue, so there are countless possible paths for teachers to feel and perceive themselves - or not - professionally fulfilled. The analysis perspective we adopted contributes to the identification of alternatives that prioritize the exercise of the profession combined with life quality.
\end{abstract}

Keywords: Teaching. Professional qualification. Career fulfillment. 


\section{Introdução}

Este estudo é voltado ao contexto formativo de professores da educação superior, profissionais com poder de exercer papel ativo e mediador de transformações sociais, influenciadores ao mesmo tempo que influenciados pelo desenvolvimento de seu trabalho. Na medida em que aspectos pessoais e sociais se entrelaçam, acreditamos que a trajetória acadêmica de professores, iniciada na graduação e acompanhada por investimentos realizados em termos de formação continuada, tem muito a revelar sobre o cenário da educação superior atual do Brasil.

O sistema nacional de ensino superior passou por várias transformações e reconfigurações ao longo dos anos. Na década de 1930, a urbanização e a industrialização trouxeram a esperança de um futuro melhor para os filhos daqueles que desde sempre tiraram seu sustento do trabalho braçal - e o caminho para esse futuro era e sempre foi a educação. Em 1968, o sistema de prova de vestibular foi adotado com a justificativa de democratizar o acesso ao ensino superior (BRAGHINI, 2014).

Na década seguinte, a ditadura militar passou a incentivar a privatização do ensino superior, o que gerou um crescimento desenfreado de instituições (GHIRALDELLI JúNIOR, 2009). Silva (2010) reitera que o grande aumento no número de instituições de ensino superior (IES) privadas no país foi produto da desigualdade quanto ao ingresso no ensino público, acrescentando que tais instituições precisaram ampliar com mais urgência o corpo docente dos cursos para atender à demanda crescente.

A política federal de expansão da educação superior brasileira pode ser relacionada, entre 2003 e 2014, ao Programa Universidade para Todos (ProUni) e ao Programa de Financiamento Estudantil (FIES), que Chaves e Amaral (2016) caracterizam como financiadores do setor privado. Em 2004 foi criado o Sistema Nacional de Avaliação da Educação Superior (SINAES), com a finalidade de avaliar instituições, cursos e desempenho de estudantes (INEP, 2015). Ainda assim, se em 2004 havia cerca de três milhões de estudantes, os resultados do Censo de 2016 apontaram a existência de 34.366 cursos de graduação ofertados em 2.407 IES e 8.052.254 de estudantes matriculados - mais que o dobro de 2004 (INEP, 2018).

Problemas graves permanecem presentes principalmente em se tratando da região norte do Brasil. No estado do Pará, em 2019, nenhuma universidade alcançou o conceito máximo do Índice Geral de Cursos (IGC), segundo dados divulgados pelo INEP, e cinco instituições ficaram proibidas de abrir novas vagas e de fechar contratos com programas como o FIES e ProUni (VILARINS, 2020).

Há muito a ser considerado também quanto ao profissional que chega às salas de aula das nossas universidades. Desde a Lei № 9.394, de 20 de dezembro de 1996, foram estabelecidas diretrizes e bases da educação nacional com a determinação de que pelo menos um terço do corpo docente de cursos universitários tivesse titulação acadêmica de mestrado ou doutorado (BRASIL, 1996). Deste modo, a pósgraduação stricto sensu adquiriu um aspecto central, relacionado ao reconhecimento e à legitimação da atuação de professores pesquisadores.

Em todo o caso, a titulação pode ser compreendida como a ponta do iceberg da formação do professor universitário. Outras variáveis devem ser consideradas, inclusive quanto aos ideais que cada professor constrói para si e o espaço criado para realizá-los. De acordo com Huberman (2007), encarar a docência como uma 
atividade profissional implica compreender que a vivência da carreira de professor não é estática. Ao longo dela, o professor passa por fases marcadas pelo entusiasmo ou pela indiferença, por expectativas e frustações, pela busca da ressignificação da prática ou pelo conservadorismo e pelo comprometimento ou pelo distanciamento. Compreender o professor em sua complexidade humana contribui para o conhecimento de trajetórias em que desempenho profissional e qualidade de vida possam caminhar juntos.

É nesta direção que este estudo descritivo se constitui, em um sentido que o aproxima de uma investigação explicativa (GIL, 2002) e com o objetivo de relacionar a avaliação subjetiva de satisfação profissional a investimentos na área realizados por professores do ensino superior de um curso de bacharelado e outro de licenciatura. A interpretação dos resultados demarcados por tais relações foi pautada na identificação de relações funcionais entre eventos, nos moldes da Análise do Comportamento.

\section{Desenvolvimento}

Uma breve apresentação de princípios analítico-comportamentais se faz necessária para dar sentido à interpretação dos resultados deste estudo. A diferenciação entre contingências de reforçamento positivo e negativo, acompanhada da noção de comportamento governado por regras, subsidia a identificação de relações entre emoções, pensamentos e ações enquanto trocas sociais. Ganha destaque, assim, a importância da opção por alternativas que permitam a realização profissional em contexto de realização pessoal.

\section{Relações funcionais: contribuições da Análise do Comportamento}

A psicologia é uma ciência que ainda se encontra em busca de seu objeto de estudo, oscilando entre as palavras "mente" e "comportamento" (CASSEPP-BORGES, 2009). Por seu turno, a Análise do Comportamento reúne subjetividade e ação sob o termo "comportamento" e o define como relação do indivíduo com o ambiente físico e social. Cada um de nós apresenta função de ambiente (reforçador ou punitivo) para os demais, mas também para si próprio (TODOROV, 2007).

O modo causal de seleção por consequências é adotado pela Análise do Comportamento para a explicação comportamental por meio do destaque a três níveis de influência: ontogênese, cultura e filogênese. Nossa identidade é construída socialmente, mas não escapamos de constrangimentos genéticos. Somos seres de escolhas, mas estamos também sujeitos a reações involuntárias e à lógica que escapa do domínio da consciência, o que é destacado, por exemplo, na área de estudo das emoções (SKINNER, 1984).

Para compreendermos a influência de variáveis sociais e históricas sobre a construção da identidade, partimos de algumas premissas: toda ação tem uma função (ou significado) que a explica; ações, sentimentos e pensamentos são comportamentos e estão frequentemente inter-relacionados; e cada ser humano é único, de modo que aquilo que é motivador ou não varia entre as pessoas e mesmo entre diferentes épocas e contextos para uma mesma pessoa (DARWICH; TOURINHO, 2005; SKINNER, 1965). 
A análise funcional é a ferramenta utilizada por analistas do comportamento e, mais recentemente, por terapeutas cognitivo-comportamentais, para a compreensão do indivíduo por meio do impacto social que sofre e gera ao longo da vida (KUYKEN; PADESKY; DUDLEY, 2010; NENO, 2003, STURMEY, 2008). Sua utilização corresponde à investigação de diferentes princípios de aprendizagem, dos quais destacaremos dois: contingências operantes e regras.

De acordo com a noção de contingência, quando ações geram consequências reforçadoras, a probabilidade de que voltem a ocorrer em situações futuras semelhantes é aumentada, sendo o contrário verdadeiro no caso de consequências punitivas. Quando agimos, mudamos o mundo externo, o que altera imediatamente nosso estado emocional e gera aprendizagens de diferentes ordens, normalmente sem que percebamos claramente. Regras, por sua vez, são descrições de contingência, o que explica por que tendem a influenciar o comportamento de modo mais verbal ou consciente (BAUM, 1999).

É importante destacar que emoções são mais do que reações fisiológicas, pois estão fortemente associadas a predisposições à ação. Nomeamos o que sentimos principalmente pela inclinação que percebemos estar tendo a agir de determinada maneira. Por exemplo, raiva e medo se assemelham em nível fisiológico, mas tendência a atacar é diferente de iniciativas de fuga (DARWICH; TOURINHO, 2005; SKINNER, 1974).

Mantemos determinados padrões de comportamento quando eles nos colocam em contato com contingências de reforçamento. O reforçamento é dito positivo quando a ação gera algo motivador, como elogio ou sorriso, e negativo quando é seguido pela retirada ou pela não apresentação de algo desestabilizador, como grito ou ameaça. O reforçamento positivo explica, portanto, meios de empoderamento genuíno, abertura para iniciativas, reconhecimento de valores pessoais e dos demais, assim como sensação de bem-estar. Por outro lado, o reforçamento negativo perpetua atitude de esquiva e ansiedade. Ainda que por caminhos opostos, as duas contingências compartilham o fato de nos manterem produtivos (SKINNER, 1965).

Guilhardi (2002) apresenta noções de autoestima, autoconfiança e responsabilidade que, reunidas, convidam à reflexão acerca de escolhas e impactos gerados por elas. Segundo ele, autoestima é o sentimento de amor que um indivíduo nutre por si próprio e que cresce mais facilmente quando ele é reconhecido e admirado socialmente por ser quem é, com seus pontos fortes e dificuldades. Assim, sucesso e fracasso não se tornam medidas de quem somos ou do valor pessoal que temos.

Autoconfiança está mais relacionada a acertos, sendo necessário, portanto, agir, ousar, tomar iniciativas e, portanto, correr riscos para que o sucesso alimente tal sentimento. Além disso, é importante perceber o valor de cada avanço. Pensar sobre si próprio como capaz também depende do olhar que é dirigido a conquistas, mesmo quando são aparentemente banais (GUILHARDI, 2002).

Responsabilidade é um termo que expressa vivências diferentes, dependentes do contato com reforçamento positivo ou negativo. Quando reforçamento negativo é o principal incentivador das atitudes tomadas, o cumprimento de obrigações acontece muitas vezes a qualquer preço. Ser responsável evita punições e gera estresse e sentimentos de desamparo e angústia. Por outro lado, responsabilidade pode estar relacionada ao contato com reforçamento positivo, de modo que prazer deriva de 
se fazer o que precisa ser feito. Quando obrigações correspondem a escolhas significativas, a pessoa não se definiria simplesmente como responsável, embora o seja, mas como realizada e gratificada (GUILHARDI, 2002).

A seguir, acompanhamos seis professores universitários em seus processos formativos em busca de compreender o que diferencia aqueles que se dizem muito satisfeitos daqueles muito insatisfeitos na área profissional. Este estudo foi aprovado pelo Comitê de Ética em Pesquisa da Universidade da Amazônia (parecer $n^{\circ}$ 3.504.536 e CCAE: 12914419.8.0000.5173).

\section{Relações funcionais: contribuições da Análise do Comportamento}

A coleta de dados foi realizada por meio da aplicação de um questionário on-line e de buscas na Plataforma Lattes do Conselho Nacional de Desenvolvimento Científico e Tecnológico (CNPq), neste caso em referência à produtividade dos participantes. Assim sendo, os dados refletem tanto relatos dos participantes quanto ações cujos resultados se encontram registrados publicamente.

O questionário partiu da identificação dos participantes (gênero e data de nascimento) para a identificação de detalhes do percurso profissional realizado (curso de graduação e maior titulação, incluindo os anos de término de ambos, e ano de início da atuação profissional). Além disso, as seguintes variáveis foram investigadas: (a) habilidades adquiridas no curso de graduação que fundamentaram a atuação como professor (com cinco possibilidades de escolha, além da opção "outros"); (b) participação em diferentes tipos de evento nos últimos três anos (com nove possibilidades de escolha, além das opções "outros" e "nenhum"); e (c) grau de satisfação profissional, dividida entre formação inicial e continuada (com as alternativas "muito insatisfeito", "insatisfeito", "indiferente", "pouco satisfeito", "satisfeito" e "muito satisfeito" para cada um dos momentos).

Dos 16 professores que inicialmente responderam a um questionário on-line, em janeiro de 2020, oito estavam vinculados a um curso de licenciatura (Letras) e outros oito a um curso de bacharelado (Administração). Nos dois casos, cinco se declararam do gênero masculino e três, do feminino. Os respondentes do curso de licenciatura estavam na faixa etária de 20 a 50 anos, e os do curso de bacharelado eram mais velhos, na faixa etária de 40 a 60 anos. No limite superior de idade estava um respondente de 60 anos e no inferior, uma respondente de 27 anos.

A relação entre o grau de satisfação dos participantes com a formação inicial e continuada, no sentido da trajetória profissional que construíram, permitiu a avaliação de uma variável temporal. Seis categorias foram criadas a partir das respostas obtidas: "muito satisfeito", "muito insatisfeito", "satisfeito", "insatisfeito", "de satisfeito a muito satisfeito, "de pouco satisfeito a satisfeito" e "de muito satisfeito para satisfeito".

Seis respondentes das categorias mais extremas (identificadas como "muito satisfeito" e "muito insatisfeito" na formação inicial e ao longo da carreira) foram selecionados para participar deste estudo e divididos em dois grupos: Grupo de Satisfação (GS) e Grupo de Insatisfação (GI). Foram excluídos três respondentes com mais de 50 anos e todos os quatro respondentes entre 27 e 46 anos.

Um código alfanumérico foi utilizado para a identificação dos participantes, iniciando com "S" ou "I", conforme inseridos no GS ou no GI, seguido por "B" ou "L", de acordo 
com o curso de vinculação ser bacharelado ou licenciatura, e por numeração de 1 a 3, indicativa de ordem decrescente de idade. Assim sendo, SB1 e IL1 são os participantes mais velhos do GS e do GI, respectivamente, sendo que o primeiro cursou bacharelado e o segundo, licenciatura.

No Quadro 1 estão dispostos os participantes, com suas respectivas idades, e separados, quanto ao grau de satisfação, nos grupos GS e GI.

\begin{tabular}{|l|l|l|}
\hline \multicolumn{2}{|c|}{ Quadro 1 - Composição dos grupos } \\
\hline Participantes & Idade & Grupo \\
\hline SB1 & 60 & \multirow{3}{*}{ Satisfação (GS) } \\
\hline SB2 & 54 & \\
\hline SB3 & 49 & \multirow{2}{*}{ Insatisfação (GI) } \\
\hline IL1 & 56 & \\
\cline { 1 - 2 } IB1 & 52 & \\
\hline IL2 & 44 & \\
\hline
\end{tabular}

O GS foi composto apenas por bacharéis (SB1, SB2 e SB3) e o GI, por um bacharel e dois licenciados (IB1, IL1 e IL2). Considerando ambos os grupos, os participantes tinham entre 44 (IL2, do GI) e 60 anos (SB1, do GS), ficando a média de idade em cerca de 53 anos. Apenas IL2 era do gênero feminino.

Relações entre avaliação subjetiva de satisfação profissional e investimentos na área foram fundamentadas em nove conjuntos de variáveis: (a) idade; (b) formação inicial; (d) maior titulação; (e) início da carreira docente; (g) competências didáticopedagógicas adquiridas na formação inicial; (h) participação em eventos científicos recentes; e (i) produção bibliográfica, técnica e artística/cultural. O tempo decorrido desde a finalização das etapas que constituem a formação e a carreira docente foi considerado, bem como a idade atual a cada momento.

$\mathrm{Na}$ Tabela 1 situamos os participantes ao longo do tempo (coluna identificada com "Partic."), incluindo a idade atual (coluna identificada com "Idade"), bem como a idade que tinham quando da conclusão da formação inicial e o tempo decorrido desde então (coluna identificada com "Graduação"), a idade que tinham quando iniciaram a carreira docente o tempo decorrido desde então (coluna identificada com "Docência") e a idade que tinham quando concluíram o curso referente à maior titulação que possuem e o tempo decorrido desde então (coluna identificada com "Titulação"), com a indicação do maior grau alcançado (coluna identificada com "Maior Titulação").

Tabela 1 - Formação inicial e continuada

\begin{tabular}{|c|c|c|c|c|c|c|c|c|}
\hline \multirow[b]{2}{*}{ Partic. } & \multirow[b]{2}{*}{ Idade } & \multicolumn{2}{|c|}{ Graduação } & \multicolumn{2}{|c|}{ Docência } & \multicolumn{2}{|c|}{ Titulação } & \multirow{2}{*}{$\begin{array}{l}\text { Maior } \\
\text { Titulação }\end{array}$} \\
\hline & & Idade & Tempo & Idade & Tempo & Idade & Tempo & \\
\hline SB1 & 60 & 37 & 23 & 45 & 15 & 49 & 11 & mestre \\
\hline SB2 & 54 & 26 & 28 & 44 & 10 & 46 & 8 & doutor \\
\hline SB3 & 49 & 24 & 25 & 31 & 18 & 42 & 7 & mestre \\
\hline IL1 & 56 & 23 & 33 & 20 & 36 & 51 & 6 & doutor \\
\hline IB1 & 52 & 35 & 17 & 37 & 15 & 44 & 8 & mestre \\
\hline IL2 & 44 & 22 & 22 & 29 & 15 & 26 & 18 & mestre \\
\hline
\end{tabular}

Em média, os participantes do GS e do GI, respectivamente, 54 e 51 anos de idade, concluíram a graduação com 29 e 27 anos, iniciaram a carreira docente aos 40 e 29 anos e alcançaram a maior titulação aos 46 e 40 anos. Tais números situam os 
participantes insatisfeitos como mais jovens e também mais precoces que os satisfeitos, mas em um ponto a diferença é bastante marcante: ingressaram na docência, em média, 11 anos antes.

Podemos desdobrar dos dados ainda algumas outras considerações. O doutor do GS (SB2) e o do GI (IL1) têm idades aproximadas, mas SB2 terminou o doutorado cinco anos antes e ingressou na docência 22 anos depois. SB1 foi quem ingressou na docência há mais tempo e, dentre os mestres, quem adquiriu tal título mais tardiamente. IL2 foi a mais jovem dos dois grupos nas três categorias investigadas: conclusão da graduação, idade em que ingressou na docência e com que concluiu a formação mais recente (mestrado). Ela, no entanto, é professora há tanto tempo quanto IB1 e SB1, mais velhos que ela, respectivamente, oito e 16 anos.

Para além de fatores cronológicos, apresentamos, na Tabela 2, dois tipos de variáveis, referentes à avaliação pessoal acerca de aquisição de competências didático-pedagógicas no curso de graduação (coluna identificada com "Competências") e à participação recente em eventos acadêmicos (coluna identificada com "Eventos").

Competências didático-pedagógicas foram apresentadas no questionário em relação a cinco áreas de atuação: relação professor-aluno, manejo de turma, transmissão de conhecimento, uso de recursos tecnológicos e avaliação. Os respondentes deveriam indicar aquelas que consideram ter adquirido ao longo da formação inicial, possibilitando, assim, a identificação de um máximo de cinco pontos fortes no curso de graduação.

Quanto à participação em eventos acadêmicos nos últimos três anos, foram listadas oito alternativas: oficinas, minicursos, fóruns, conferências, congressos, simpósios, reuniões pedagógicas e cursos de aperfeiçoamento. Os dados resultantes deveriam refletir o engajamento dos participantes em atividades nas quais são abertos espaços tanto para a exposição de trabalhos, quanto para a vivência mais passiva de trocas com outros profissionais e estudantes. Procuramos, em linhas gerais, contrastar informações acerca do passado dos participantes a outras mais recentes.

Tabela 2 - Competências e participação em eventos

\begin{tabular}{lll}
\hline Participante & Competências & Eventos \\
\hline B1 & 2 & 4 \\
SB2 & 1 & 6 \\
SB3 & 3 & 2 \\
IL1 & 5 & 8 \\
IB1 & 2 & 4 \\
IL2 & 4 & 6 \\
\hline \multicolumn{2}{l}{}
\end{tabular}

Todos os participantes identificaram ao menos uma competência didáticopedagógica adquirida na graduação, enquanto IL1 indicou ter adquirido todas elas. A média das respostas do GS correspondeu a 2 e a do GI, a 3,7, indicando que, quanto a este aspecto, os participantes identificados como insatisfeitos avaliaram mais positivamente a aquisição de tais competências no período da graduação do que os identificados como satisfeitos.

Comparando os resultados dos dois licenciados (GI) com os dos quatro bacharéis (três deles no GS), no entanto, a média encontrada foi, respectivamente, de 4,5 e 2. É esperado que cursos de licenciatura sejam mais direcionados para a 
transmissão das competências investigadas do que os de bacharelado. No entanto, como este estudo é voltado a professores, tal variável permanece relevante por permitir comparar bacharéis que optaram pela docência àqueles que teoricamente optaram pelo magistério desde a graduação, buscando instrumentalização para tanto em um curso de licenciatura.

Quanto à participação em eventos nos últimos três anos, a presença mínima equivaleu a dois (SB3), sendo que IL1 se fez presente nos oito tipos de evento que foram listados. As médias resultantes dos dados dos participantes do GS e do GI corresponderam, respectivamente, a 4 e 6 . Os participantes insatisfeitos, portanto, demonstraram estar mais engajados na participação em eventos acadêmicos, pelo menos nos últimos anos.

Em linhas gerais, os participantes do GS tenderam a avaliar mais negativamente a graduação do que os do Gl e são menos engajados na participação em eventos acadêmicos.

A Tabela 3 deveria apresentar a produção bibliográfica dos participantes nos últimos três anos. A busca nos respectivos currículos, no entanto, resultou em obras com início em 2000, no caso do GS, e 2002, no caso do GI, que cessaram em 2015, com exceção de projetos de extensão que finalizaram em 2016 (de IL1 e IL2). Utilizamos tais dados por considerarmos que são relevantes à análise que nos propusemos a realizar.

Vale destacar que apenas dois participantes (SB1 e SB2) estavam com os currículos atualizados quando da verificação que realizamos. Todos os demais atualizaram o currículo pela última vez em outubro de 2018 (IL1) ou entre fevereiro (SB3 e IL2) e março de 2019 (IB1).

Tabela 3 - Produção bibliográfica

\begin{tabular}{llllll}
\hline Participante & Artigos & Livros & Capítulos & Extensão & Anais \\
\hline SB1 & 5 & 0 & 0 & 0 & 2 \\
SB2 & 0 & 1 & 2 & 0 & 0 \\
SB3 & 0 & 1 & 1 & 0 & 0 \\
SUBTOTAL & 5 & 2 & 3 & 0 & 2 \\
IL1 & 5 & 1 & 1 & 3 & 14 \\
IB1 & 2 & 1 & 0 & 2 & 0 \\
IL2 & 0 & 0 & 0 & 4 & 1 \\
SUBTOTAL & 7 & 2 & 1 & 9 & 15 \\
TOTAL & 12 & 4 & 4 & 9 & 17 \\
\hline \multicolumn{5}{r}{} \\
\hline
\end{tabular}

Os participantes do GS produziram cinco artigos (SB1, entre 2013 e 2015), dois livros (SB2, em 2011, e SB3, em 2002) e três capítulos de livro (SB2, em 2009 e 2010, e SB3, em 2002), além de terem publicado dois trabalhos ou resumos em anais de evento (SB1, em 2012 e 2013). Os participantes do GI produziram sete artigos (IL1, cinco entre 2007 e 2012, e IB1, dois, em 2006 e 2007), dois livros (IL1, em 2014, e IB1, em 2008) e um capítulo de livro (IL1, em 2014), assim como publicaram 15 trabalhos ou resumos em anais de evento (14 de IL1, entre 2006 e 2014, e um de IL2, em 2009). Além disso, os três participantes do Gl coordenaram um total de nove projetos de extensão (IL1, em 2012, 2014 e 2016; IB1 entre 2010 e 2011 e de 2007 a 2011; e IL2 em 2003, 2004, 2008 e 2016).

Assim sendo, os participantes do GS produziram $75 \%$ dos capítulos de livro (três de um total de quatro), $42 \%$ dos doze artigos (cinco de um total de 12) e 12\% dos 
trabalhos ou resumos em anais de eventos (dois de um total de 17). O total de livros publicados (quatro) foi igual nos dois grupos, e o destaque maior do GI se deu na coordenação de $100 \%$ dos projetos de extensão (nove).

Quanto à produção técnica dos últimos três anos, oito tópicos foram derivados da pesquisa realizada no currículo dos participantes: assessoria e consultoria, programas de computador sem registro, processos e técnicas, trabalhos técnicos, editoração, entrevistas, mesas redondas, programas e comentários na mídia, redes sociais, websites e blogs, e outras produções técnicas. Nesta área, portanto, foram considerados apenas os tópicos em que havia alguma produção documentada. Tais dados estão dispostos na Tabela 4, juntamente com a produção artística/cultural.

Tabela 4 - Produção técnica e artística/cultural

\begin{tabular}{lll}
\hline Participante & Produção técnica & Produção Artística/Cultural \\
\hline SB1 & 8 & 0 \\
SB2 & 5 & 0 \\
SB3 & 13 & 0 \\
SUBTOTAL & 26 & 0 \\
IL1 & 6 & 5 \\
IB1 & 1 & 0 \\
IL2 & 1 & 0 \\
SUBTOTAL & 8 & 0 \\
TOTAL & 34 & 5 \\
\hline
\end{tabular}

Os participantes do GS apresentam $76 \%$ do total de produções técnicas nos últimos três anos (26 diante de oito do $\mathrm{Gl}$ ). Enquanto o mínimo e o máximo de produção corresponderam, respectivamente, a cinco (SB2, o único doutor do grupo) e 13 (SB3), no GS, dois participantes do GI contribuíram com uma produção, cada (IB1 e IL2) e um deles, com seis (IL1, o único doutor). Assim, o doutor que se mostra insatisfeito ainda produziu mais do que o satisfeito, mas a contribuição dos mestres do GS (21) é de $91 \%$ em comparação com a do GI (dois).

Quanto à produção artística/cultural, IL1 tem uma "produção cênica", em 2016, e um total de quatro, entre 2003 e 2014, em "outras produções artísticas/culturais". Vale ressaltar que os dados recentes, apresentados na Tabela 4, contrastam à produção bibliográfica, ausente nos currículos a partir de 2015 , dispostos na Tabela 3.

Em síntese, investigamos variáveis que correspondem a diferentes ações empreendidas no âmbito estudantil e profissional (apresentados nas tabelas) e o grau de satisfação associado (presente no Quadro 1), comparando os resultados dos dois grupos de participantes.

\section{Satisfação e insatisfação frente a frente}

Tendo situado o grau de satisfação dos participantes e o percurso profissional realizado, tentamos desdobrar hipóteses que sustentem as relações estabelecidas.

Para uma análise mais pontual, iniciamos nos perguntando por que SB1, SB2 e SB3 se destacaram quanto à satisfação experienciada. $O$ que eles têm feito ao longo dos anos em que a satisfação de estudar e exercer a docência os acompanha? 
SB1 tem 60 anos, está formado há 23 anos, avaliou negativamente o curso de graduação quanto às competências didático-pedagógicas adquiridas, é mestre há 19 anos, atua no ensino superior há 15 anos, publicou cinco artigos entre 2013 e 2015 e, em 2012 e 2013, um trabalho e um resumo, respectivamente, em anais de eventos, participou de quatro tipos de eventos e concluiu oito produções técnicas nos últimos três anos.

SB2 tem 54 anos, está formado há 28 anos, avaliou de forma totalmente negativa o curso de graduação quanto às competências didático-pedagógicas adquiridas, é doutor há três anos, atua no ensino superior há dez anos, publicou dois capítulos de livro, um em 2009 e outro em 2010, um livro em 2011, nos últimos três anos participou de seis tipos de eventos e concluiu cinco produções técnicas.

SB3 tem 49 anos, está formado há 25 anos, avaliou relativamente bem o curso de graduação quanto às competências didático-pedagógicas adquiridas, é mestre e atua no ensino superior há 18 anos, escreveu um capítulo de livro e um livro em 2002, nos últimos três anos participou de dois tipos de eventos e concluiu treze produções técnicas.

Temos três homens, professores do curso de bacharelado em Administração, entre 49 e 60 anos e com mais de 20 anos de formados. No geral, os participantes avaliaram negativamente o curso de graduação que fizeram quanto à preparação ao exercício da docência. A titulação é igual a dos participantes do Gl: dois mestres e um doutor. O tempo que permanecem com a mesma titulação varia de sete a 11 anos. Em relação à atuação como professores, os limites mínimo e máximo são, respectivamente, de três e 18 anos. O total de participação em eventos, variando entre dois e seis, reflete que dois participantes ultrapassaram a média dos grupos. A produção de um total de cinco artigos, três capítulos de livro, dois livros e duas publicações de trabalhos e resumos em anais de eventos ficou restrita ao período entre 2012 e 2013, mas nos últimos três anos o grupo concluiu 26 produções técnicas.

Assim sendo, ser homem parece ter as suas vantagens em termos de autoavaliação profissional, bem como ter mais de 40 anos e estar formado há mais de 20 anos. Um outro fator motivador pode ser a publicação de artigos, capítulos de livro ou livros, ainda que em um período específico do passado. Atuar no curso de bacharelado em Administração também parece favorecer, apesar da avaliação no geral negativa quanto ao preparo ao exercício da docência na graduação. O que não parece fazer diferença entre eles: a titulação alcançada, o tempo de atuação na docência e de permanência com a mesma titulação e a frequência da participação em eventos acadêmicos. Não parece fazer falta o engajamento em projetos de extensão.

Quanto aos participantes do GI, IL1 tem 56 anos, está formado há 33 anos, avaliou de forma totalmente positiva o curso de graduação quanto às competências didático-pedagógicas adquiridas, é doutor há 11 anos, atua no ensino superior há 36 anos, publicou cinco artigos entre 2007 e 2012, um capítulo de livro e um livro em 2014, coordenou três projetos de extensão entre 2012 e 2016, tem 14 resumos em anais de eventos entre 2006 e 2014, nos últimos três anos participou de oito tipos de eventos acadêmicos e concluiu seis produções técnicas, além de ter produções artísticas, uma no item "artes cênicas", em 2016, e quatro em "outras produções artísticas/culturais", entre 2003 e 2014.

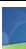


IB1 tem 52 anos, está formado há 17 anos, avaliou negativamente o curso de graduação quanto ao preparo para a docência, é mestre e atua no ensino superior há 15 anos, publicou um artigo em 2006, outro em 2007 e um livro em 2008, coordenou dois projetos de extensão de 2007 a 2011 e de 2010 a 2011, nos últimos três anos participou de quatro tipos de eventos e concluiu uma produção técnica.

IL2 tem 44 anos, está formada há 22 anos, adquiriu na graduação quatro das cinco competências listadas, é mestre há 18 anos, atua no ensino superior há 15 anos, coordenou quatro projetos de extensão entre 2003 e 2016, publicou um resumo de trabalho completo em anais, em 2009, nos últimos três anos participou de seis tipos de eventos e concluiu uma produção técnica.

Aqui temos uma mulher e dois homens. Ela é professora do curso de Letras, assim como um dos colegas do gênero masculino, e é a mais nova do grupo, com 44 anos, sendo que os outros têm mais de 50 anos. O tempo de formação, de 17, 22 e 33 anos, não é curto, mas também não é homogêneo. No geral, os participantes avaliaram positivamente o curso de graduação que fizeram quanto à preparação ao exercício da docência. Dois são mestres e um é doutor, e todos permaneceram com a mesma titulação de cinco a 18 anos, sendo que dois atuam como professores há 15 anos e um, há mais que o dobro desse tempo: 36 anos. A participação em eventos, nos últimos anos, se manteve na média e acima dela, em comparação com os resultados do GS.

Em se tratando de ter uma vida profissional insatisfatória, aprendemos com os três participantes do Gl que ser homem também pode ser desvantajoso, bem como ter 40 anos ou mais e estar formado há mais de 17 anos. Atuar no curso de Administração desta vez parece ser mais um fator negativo, assim como o longo tempo de atuação na docência (superior a 15 anos) e, inclusive, participar em eventos acadêmicos. Avaliar positivamente o curso de graduação quanto a ter sido um espaço de aquisição de competências para a docência também não ajudou. $O$ que não parece fazer diferença entre os participantes é o tempo de permanência com a mesma titulação e mesmo a alta titulação alcançada, pois mestres e doutor estão igualmente insatisfeitos. Produções bibliográfica, técnica e artística/cultural também não parecem fazer sentido quando se trata de avaliar a satisfação profissional.

Comparando os dois grupos, vemos que a produção bibliográfica do Gl é inferior à do GS no quesito capítulo de livro (três no GS e um no Gl) e os dois grupos ficam empatados quanto à publicação de livros (dois), mas a produção do Gl é maior quanto à publicação de artigos (sete no GI e cinco no GS) e de trabalhos ou resumos em anais de eventos (15 no GS e apenas dois no $\mathrm{Gl}$ ). O destaque maior do GI está, no entanto, na coordenação de projetos de extensão, com nove ocorrências (e nenhuma no GS). Na produção técnica e artística/cultural o grupo se fez presente, mas com menos de um terço da produção do GS (oito no GI e 26 no GS). No entanto, IL1 participou de oito tipos de eventos acadêmicos, ultrapassando todos os seis participantes (e, inclusive, também todos os 18 respondentes iniciais), além de ser a única dentre os participantes a ter produções artísticas/culturais.

Analisamos relatos de seis participantes, três deles que admitem ter estado muito satisfeitos e três, muito insatisfeitos com seus estudos e com a construção de suas carreiras, assim permanecendo ao longo dos anos e até hoje. Buscamos relacionar a sensação de satisfação ou insatisfação principalmente às atividades profissionais nas quais costumaram se engajar. Uma pergunta foi dirigida ao modo de pensar, 
quanto à avaliação das capacidades para o exercício da docência que porventura adquiriram ao longo do curso de graduação. Voltada ao passado, ela lança luz à forma de avaliação de que os participantes se valem em se tratando de algo exterior a eles, embora características pessoais também transpareçam quando, por exemplo, determinadas competências são adquiridas ou não.

Comparar os participantes do GS com os GI resultou na percepção de variações importantes entre eles, para além dos pontos que têm em comum. A investigação é aprofundada com base nos dados dispostos na Tabela 5.

\begin{tabular}{|c|c|c|c|c|c|c|c|}
\hline \multirow[b]{2}{*}{ Idade } & \multirow{2}{*}{$\begin{array}{l}\text { Tempo } \\
\text { Titulação }\end{array}$} & \multirow{2}{*}{$\begin{array}{l}\text { Tempo } \\
\text { Graduacão }\end{array}$} & \multirow{2}{*}{$\begin{array}{l}\text { Tempo } \\
\text { Docência }\end{array}$} & \multirow[b]{2}{*}{ Evento } & \multicolumn{3}{|l|}{ Produção } \\
\hline & & & & & Biblio. & Técn. & Art./Cult. \\
\hline 60 & & 23 & 15 & 4 & & & \\
\hline 54 & 7 a 11 & 28 & 10 & 6 & 12 & 26 & 0 \\
\hline 49 & & 25 & 18 & 2 & & & \\
\hline 56 & & 33 & 36 & 8 & & & \\
\hline 52 & 5 a 18 & 17 & 15 & 4 & 34 & 8 & 5 \\
\hline 44 & & 22 & 15 & 6 & & & \\
\hline
\end{tabular}

Fonte: Próprias autoras (2020).

Ao descrever características pessoais e da vida profissional, incluindo aí o grau de satisfação experienciado, percebemos que ser homem ou mulher, atuar no curso de Administração ou no de Letras, estar formado há mais de 15 anos, ser mestre ou doutor e permanecer com a mesma titulação por cinco, sete, 15 ou 18 anos são variáveis não preditoras do grau de satisfação profissional. Além disso, aqueles participantes mais críticos quanto à graduação, que acreditam que não conseguiram adquirir, naquele período, as competências necessárias para a docência, são os mais satisfeitos profissionalmente. Também é mais satisfeito quem participa menos de eventos acadêmicos, tem menor produção bibliográfica e artística/cultural e não participa de projetos de extensão, mas investe muito em produção técnica.

Iniciamos aqui comparações mais pontuais de duplas de participantes de grupos diferentes com dois mestres do gênero masculino.

SB3 e IB1 são mestres e professores do curso de bacharelado em Administração, sendo o primeiro, com 49 anos, três anos mais novo que o segundo. Neste caso, o mais novo está há mais tempo na docência (três anos), terminou o mestrado também há mais tempo (um ano) e está muito satisfeito com sua vida profissional, ao contrário do colega. As atividades acadêmicas e profissionais não diferenciam SB3 e IB1 de forma significativa. SB3 participou de menos eventos científicos nos últimos três anos, mas IB1 também não tem produção em anais de eventos, SB3 e IB1 publicaram um livro e SB3 publicou também um capítulo de livro. Com treze produções técnicas, SB3 ultrapassa em muito IB1, que tem apenas uma, mas, por outro lado, coordenou dois projetos de extensão.

A comparação entre os dois participantes doutores, IL1 e SB2, demonstra que o primeiro tem sido mais ativo profissionalmente, mas tem mais que o triplo de tempo na docência que SB2. IL1, com seus 56 anos de idade e 33 anos de docência, finalizou o doutorado aos 51 anos, tem o maior número de participação em diferentes tipos de eventos acadêmicos nos últimos três anos, publicou artigos, capítulo de livro e livro, tem o maior número de publicação de trabalhos e resumos em anais de eventos e de coordenação de projetos de extensão dentre todos os participantes, além de ter uma produção técnica seis vezes maior que os demais do 
seu grupo. SB2, dois anos mais novo, com dez anos de docência e oito como doutor, também ativo no que se trata de participar de eventos científicos, publicou dois capítulos de livro e um livro, e tem uma produção técnica razoável, com apenas uma obra a menos que IL1 e a segunda maior do seu grupo.

Vale ressaltar que, ainda que cinco dentre aqueles satisfeitos e insatisfeitos exerçam a profissão há uma média de 18 anos, um dos que estão satisfeitos o faz há dez anos e um dos insatisfeitos, há 36 anos. Aí está um indicativo de que precisamos cuidar continuamente das relações que estabelecemos em longo prazo também na área profissional, principalmente quando se considera que ter mais de 40 anos favorece uma visão positiva - ou negativa - estável acerca desse âmbito de vida.

Se as variáveis que explicariam a satisfação ou a insatisfação com a profissão são múltiplas e variadas, o estabelecimento de relações funcionais entre eventos comportamentais e pessoais pode ser esclarecedor, sustentando o levantamento de hipóteses com fundamentação científica na Análise do Comportamento.

Cunha (2000) apresenta detalhes acerca do controle coercitivo, demarcado por punições e esquivas, que pode gerar reforçamento negativo ao longo da carreira de professores, posto que a produção científica se torna uma exigência constante. $O$ acúmulo de publicações em periódicos leva os professores a uma corrida marcada por concorrências e competições, resultado da produção científica individualizada, isolada e solitária. A ânsia em estar à frente dos colegas de profissão leva os professores a se tornar, em primeiro plano, pesquisadores profissionais e, em segundo plano, professores da graduação. Neste sentido, regras e contingências se somam e nos incitam a maiores detalhamentos.

Podemos considerar que regras seguidas pelos participantes direcionam suas decisões nas áreas de formação e vivência profissional, a forma como avaliam ocorrências a elas relacionadas e como se situam emocionalmente diante delas. Quanto às contingências, é esperado que satisfação ou insatisfação derive do contato contínuo com reforçamento positivo e negativo, respectivamente.

Assim sendo, realizar atividades voltadas para a docência, criar e coordenar projetos de extensão, publicar, investir em uma titulação maior podem ser formas de evitar punições. Estas podem estar implícitas em ameaças de demissão ou mesmo em demonstrações de desvalorização em diferentes frentes, além de haver a possibilidade de o trabalho ser convertido em competição entre os pares. Em tais casos, a realização de obrigações é acompanhada por mero alívio de ansiedade e, portanto, por insatisfação. Por outro lado, as mesmas atividades podem gerar motivação, alegria e, assim, satisfação, quando derivadas do estabelecimento de rotinas dinâmicas, produtivas e interessantes, assim como do fortalecimento de redes de relações e de construção, por meio do trabalho, de espaços de liberdade.

Regras e contingências estão constantemente inter-relacionadas, do mesmo modo que agir, pensar e sentir. Provavelmente não é possível que regras, isoladamente, nos preparem para a diversidade de possibilidades dos diferentes contextos e experiências de vida, e, de acordo com Baum (1999), podem tanto ajudar, quanto atrapalhar. Como exemplo, Huberman (2007) afirma que os três primeiros anos da carreira profissional correspondem a uma fase de sobrevivência e de descobertas, pois o professor iniciante se depara com o choque entre suas expectativas e a realidade do contexto educacional. Tal perspectiva se traduz no contraste entre as regras que o professor segue e as contingências com as quais se depara em seu

4


cotidiano profissional. Vale acreditar que, se o meio acadêmico não for marcado por competições e embates, o apoio de colegas pode ser muito útil no momento inicial do exercício da docência - e não apenas.

\section{Considerações finais}

De acordo com Henn (2004), geneticista e especialista em ética médica da Alemanha, abraçar com paixão a carreira de professor e pesquisador é coisa do passado, abandonada desde o final do século XIX. Atualmente, pesquisadores não baseiam suas atividades em preferências pessoais, mas em estratégias que lhes garantam o sustento. Neste sentido, o professor precisa ser capaz de buscar o espaço mais favorável ao desenvolvimento profissional e reconhecer seus pontos fortes e fracos, com ênfase no valor da flexibilidade, imprescindível para planos de carreira.

Paixão e satisfação acompanham ações que geram o contato frequente com reforçamento positivo. Por outro lado, buscar o sustento, abrindo mão de preferências, produz reforçamento negativo e insatisfação. Entre esses dois polos ainda podemos imaginar professores que se reconheçam realizados profissionalmente, afastados de um modo de viver demarcado por círculos estressantes de ansiedade e alívio. Guilhardi (2002) distingue dois tipos de responsabilidade por meio da diferenciação entre sentimento de responsabilidade, derivado de ações reforçadas negativamente, e ação responsável, associada a emoções agradáveis que acompanham o reforçamento positivo. É possível uma pessoa "trabalhar de maneira eficiente, completa, organizada etc. sob influência de contingências reforçadoras e com sentimentos agradáveis, diferentemente de trabalhar bem, com eficiência, sob influência de contingências coercitivas" (GUILHARDI, 2002, p. 23).

Objetivamos relacionar avaliação subjetiva de satisfação profissional a investimentos na área realizados por professores do ensino superior de um curso de bacharelado e outro de licenciatura. Neste sentido, buscamos identificar o contato que os participantes conseguiram gerar com reforçamento positivo ou negativo, o que revelaria a validade das regras que seguiram ou formularam acerca de escolhas que levariam a melhores resultados.

Pretendemos, portanto, destacar a necessidade de valorização da complexidade humana e da compreensão do indivíduo enquanto totalidade. Excelência profissional não deve ser um fim em si mesmo ou um objetivo isolado. O sentido da vida de cada um adquire concretude na satisfação que gera, aliada a princípios éticos que a expandem socialmente.

Dividimos os participantes em dois grupos, a fim de comparar os relatos daqueles que demonstraram favorecer o exercício da profissão e também a qualidade de vida com os daqueles que colocaram aspectos emocionais em segundo plano, intencionalmente ou não. Não derivamos, dos resultados, uma fórmula a ser seguida quanto às atitudes que um professor deve ter para que se realize profissionalmente. É possível se tornar um doutor satisfeito como SB2 ou, pelo contrário, insatisfeito como IL1, bem como ser mestre e satisfeito como SB1 e SB3 ou insatisfeito como IB1 e IL2. 
Ações e emoções estão inter-relacionadas de modo tal que levam com elas o modo como interpretamos fatores externos e internos. Assim sendo, satisfação ou insatisfação pessoal e profissional é obra particular de cada um, refletindo as trocas sociais historicamente estabelecidas no que tange ao tipo de reforçamento que é gerado a partir das atitudes tomadas.

Em outros termos, processos formativos de professores devem ser compreendidos em um contexto amplo de relações que leva em conta realizações e avaliações pessoais e sociais com impacto positivo ou negativo na vida emocional e, portanto, na qualidade de vida dos envolvidos.

Em suma, é possível fazer dos anos de docência um movimento de sucesso profissional, ainda que insatisfatório, ou um caminho de realização, como mostram, cada um a seu modo, os seis participantes cujas respostas foram avaliadas neste estudo.

\section{Agradecimentos}

O presente trabalho foi realizado com apoio da Coordenação de Aperfeiçoamento de Pessoal de Nível Superior - Brasil (CAPES) - Código de Financiamento 001.

\section{Referências}

BAUM, W. M. Compreender o behaviorismo: ciência, comportamento e cultura. Tradução: Maria Teresa Araújo Silva et al. Porto Alegre: ARTMED, 1999.

BRAGHINI, K. M. Z. A história dos estudantes "excedentes" nos anos 1960: a superlotação das universidades e um "torvelinho de situações improvisadas". Educar em Revista, Curitiba, n. 51, p. 123-144, mar. 2014. Disponível em http://www.scielo.br/scielo.php?script=sci_arttext\&pid=S0104-

40602014000100009\&lng=en\&nrm=iso\&tlng=pt. Acesso em: 10 fev. 2021.

BRASIL. Presidência da República. Lei No 9.394, de 20 de dezembro de 1996. Estabelece as diretrizes e bases da educação nacional. Diário Oficial da União, Brasília, DF, 1996. Disponível em: http://www.planalto.gov.br/ccivil_03/leis/L9394.htm\#art92. Acesso em: 21 jan. 2021.

CASSEPP-BORGES, Vicente. A ciência da mente: a Psicologia em busca de seu objeto. Interamerican journal of psychology, Porto Alegre, v. 43, n. 2, p. 425427, ago. 2009. Disponível em:

http://pepsic.bvsalud.org/scielo.php?script=sci_arttext\&pid=S003496902009000200023 . Acesso em: 21 jan. $202 \overline{1}$.

CHAVES, V. L. J; AMARAL, N. C. Política de expansão da educação superior no Brasil - o PROUNI e o FIES como financiadores do setor privado. Educar em Revista, Belo Horizonte, v. 32, n. 4, p. 49-72, Dec. 2016. Disponível em: http://www.scielo.br/scielo.php?script=sci_arttext\&pid=S010246982016000400049. Acesso em: 21 jan. 2021.

CUNHA, M. I. Ensino como mediação da formação do professor universitário. In: MOROSINI, M. C. (org.). Professor do ensino superior: identidade, docência e formação. Brasília: Instituto Nacional de Estudos e Pesquisas Educacionais, 2000. p. $45-52$.

(10)


DARWICH, R. A; TOURINHO, E. Z. Respostas emocionais à luz do modo causal de seleção por consequências. Revista brasileira de terapia comportamental e cognitiva, São Paulo, v. 7, n. 1, p. 107-118, jun. 2005. Disponível em: http://pepsic.bvsalud.org/pdf/rbtcc/v7n1/v7n1a11.pdf. Acesso em: 10 fev. 2021.

GIL, A. C. Como elaborar projetos de pesquisa. 4ª ed. São Paulo: Atlas, 2002.

GUILHARDI, H. J. Autoestima, autoconfiança e responsabilidade. In: BRANDÃO, M. Z. S.; CONTE, F. C. S.; MEZZAROBA, S. M. B. (orgs.). Comportamento Humano: tudo (ou quase tudo) que você precisa saber para viver melhor. Santo André: ESETec, 2002. p. 63-98.

GHIRALDELLI JÚNIOR, P. História da educação brasileira. 4. ed. São Paulo: Cortez, 2009.

HENN, W. Karriere mit Darwin? Evolutionäre Strategien für die Wissenschaftlerlaufbahn. Gegenworte - Hefte für den Disput über Wissen, v. 14, p. 22-25, 2004.

HUBERMAN, M. O ciclo de vida profissional dos professores. In: NÓVOA, A. (org.). Vida de professores. 2. ed. Tradução: Maria dos Anjos Caseiro, Manuel Figueiredo Ferreira. Porto, Portugal: Porto Editora, 2007, p. 31-61.

INSTITUTO NACIONAL DE ESTUDOS E PESQUISAS EDUCACIONAIS ANÍSIO TEIXEIRA (INEP). Sinaes. Brasília: MEC/Inep, 2015. Disponível em: http://inep.gov.br/sinaes. Acesso em: 15 fev. 2021.

INSTITUTO NACIONAL DE ESTUDOS E PESQUISAS EDUCACIONAIS ANÍSIO TEIXEIRA (INEP). Sinopses Estatísticas da Educação Superior - Graduação. Brasília: MEC/Inep: 2018.2 Disponível em: http://portal.inep.gov.br/web/guest/sinopses-estatisticas-da-educacao-superior. Acesso em: 15. fev. 2021.

KUYKEN, W.; PADESKY; C. A.; DUDLEY, R. Conceitualização de casos colaborativa: o trabalho em equipe com pacientes em Terapia CognitivoComportamental. Tradução: Sandra Maria Mallmann da Rosa. Porto Alegre: Artmed, 2010.

NENO, S. Análise funcional: definição e aplicação na terapia analíticocomportamental. Revista brasileira de terapia comportamental e cognitiva, São Paulo, v. 5, n. 2, p. 151-165, dez. 2003. Disponível em http://pepsic.bvsalud.org/scielo.php?script=sci_arttext\&pid=S1517-

55452003000200006\&lng=pt\&nrm=iso. Acesso em: 10 fev. 2021.

SILVA, A. K. M. da; LELIS, I. A. O. M. Trajetórias formativas dos professores dos cursos de Letras e Matemática da Universidade do Estado do Pará (UEPA). 2010. Tese (Doutorado em Educação) - Pontifícia Universidade Católica do Rio de Janeiro, Rio de Janeiro, 2010.

SKINNER, B. F. Science and human behavior. New York: Free Press/Collier MacMillan, 1965.

SKINNER, B. F. About behaviorism. New York: Vintage Books, 1974.

SKINNER, B. Selection by consequences. Behavioral and Brain Sciences, v. 7, $\mathrm{n}$. 4, p. 477-481, 1984.

(1)


STURMEY, P. Behavioral case formulation and intervention: a functional analytic approach. West Sussex, England: Wiley-Blackwell, 2008.

TODOROV, J. C. A Psicologia como o estudo de interações. Psicologia: Teoria e Pesquisa, Brasília, v. 23, n. spe, p. 57-61, 2007. Disponível em: http://www.scielo.br/scielo.php?script=sci_arttext\&pid=S0102-

$37722007000500011 \&$ Ing=pt\&nrm=iso. Acesso em: 29 jan. 2021.

VILARINS, T. Universidades não alcançam nota máxima no Estado. O Liberal, Pará, 5 jan. 2020. Caderno Amazônia. Disponível em https://www.oliberal.com/para/universidades-nao-alcancam-nota-maxima-noestado-1.226849. Acesso em: 16. fev. 2021.

Recebido: 29/02/2020

Aprovado: $16 / 04 / 2021$

Como citar: JERONIMO, V. A. O.; DARWICH, R. A. Formação de professores do ensino superior e satisfação profissional. Revista de Estudos e Pesquisas sobre Ensino Tecnológico (EDUCITEC), v. 7, e112621, 2021.

\section{Contribuição de autoria:}

Viviane Assunta Oliveira Jeronimo - Conceituação, curadoria de dados,análise formal, aquisição de financiamento, investigação, validação, visualização, escrita (rascunho original) e escrita (revisão e edição).

Rosângela Araújo Darwich - Conceituação, análise formal, metodologia, administração de projeto, supervisão, validação, visualização e escrita (revisão e edição).

Direito autoral: Este artigo está licenciado sob os termos da Licença Creative CommonsAtribuição 4.0 Internacional.

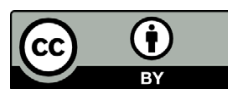

